\title{
Metabolism and Biodegradation of Spacecraft Cleaning Reagents by Strains of Spacecraft-Associated Acinetobacter
}

\author{
Rakesh Mogul, Gregory A. Barding Jr., Sidharth Lalla, Sooji Lee, Steve Madrid, Ryan Baki, \\ Mahjabeen Ahmed, Hania Brasali, Ivonne Cepeda, Trevor Gornick, Shawn Gunadi, Nicole Hearn, \\ Chirag Jain, Eun Jin Kim, Thi Nguyen, Vinh Bao Nguyen, Alex Oei, Nicole Perkins, Joseph Rodriguez, \\ Veronica Rodriguez, Gautam Savla, Megan Schmitz, Nicholas Tedjakesuma, and Jillian Walker
}

\begin{abstract}
Spacecraft assembly facilities are oligotrophic and low-humidity environments, which are routinely cleaned using alcohol wipes for benchtops and spacecraft materials, and alkaline detergents for floors. Despite these cleaning protocols, spacecraft assembly facilities possess a persistent, diverse, dynamic, and low abundant core microbiome, where the Acinetobacter are among the dominant members of the community. In this report, we show that several spacecraft-associated Acinetobacter metabolize or biodegrade the spacecraft cleaning reagents of ethanol (ethyl alcohol), 2-propanol (isopropyl alcohol), and Kleenol 30 (floor detergent) under ultraminimal conditions. Using cultivation and stable isotope labeling studies, we show that ethanol is a sole carbon source when cultivating in $0.2 \times \mathrm{M} 9$ minimal medium containing $26 \mu \mathrm{M} \mathrm{Fe}\left(\mathrm{NH}_{4}\right)_{2}\left(\mathrm{SO}_{4}\right)_{2}$. Although cultures expectedly did not grow solely on 2-propanol, cultivations on mixtures of ethanol and 2-propanol exhibited enhanced plate counts at mole ratios of $\leq 0.50$. In support, enzymology experiments on cellular extracts were consistent with oxidation of ethanol and 2-propanol by a membrane-bound alcohol dehydrogenase. In the presence of Kleenol 30, untargeted metabolite profiling on ultraminimal cultures of Acinetobacter radioresistens 50v1 indicated (1) biodegradation of Kleenol 30 into products including ethylene glycols, (2) the potential metabolism of decanoate (formed during incubation of Kleenol 30 in $0.2 \times \mathrm{M} 9$ ), and (3) decreases in the abundances of several hydroxy- and ketoacids in the extracellular metabolome. In ultraminimal medium (when using ethanol as a sole carbon source), A. radioresistens 50v1 also exhibits a remarkable survival against hydrogen peroxide $\left(\sim 1.5-\log\right.$ loss, $\sim 10^{8}$ colony forming units (cfu) $/ \mathrm{mL}, 10 \mathrm{mM} \mathrm{H}_{2} \mathrm{O}_{2}$ ), indicating a considerable tolerance toward oxidative stress under nutrient-restricted conditions. Together, these results suggest that the spacecraft cleaning reagents may (1) serve as nutrient sources under oligotrophic conditions and (2) sustain extremotolerances against the oxidative stresses associated with low-humidity environments. In perspective, this study provides a plausible biochemical rationale to the observed microbial ecology dynamics of spacecraft-associated environments. Key Words: Acinetobacter-Planetary protection-Extreme survival-Metabolism-Spacecraft—Cleaning-Bioburden. Astrobiology 18, 1517-1527.
\end{abstract}

\section{Introduction}

S PACECRAFT ASSEMBLY, TEST, launch, and operational procedures that minimize the biological contamination of explored environments are critical to ensuring the integrity of future life-detection missions, and in mitigating irreversible impacts to any native biochemical states (Space Studies Board, 2000, 2006). To assist in reducing the probability of contamination, NASA planetary protection requirements for
Mars include the assembly of spacecraft in clean room facilities, trajectory biasing for outgoing spacecraft, low impact probabilities for orbiting spacecraft, and partial sterilization of lander and rover spacecraft (at the sub- or full-system levels) (NASA, 2011; Frick et al., 2014).

For spacecraft assembly, all Mars-bound spacecraft (orbiters, landers, and rovers) are additionally subject to requirements necessitating clean rooms with high particulate control (ISO class 8 , Class 100,000 or better), proper garmenting procedures 
for human personnel in the clean rooms (e.g., bunny suit coveralls), and routine cleaning procedures for spacecraft, surfaces, and floors within the assembly facilities (NASA, 2011; Frick et al., 2014). The commonly used cleaning reagents for these purposes are ethanol (ethyl alcohol) and 2-propanol (isopropyl alcohol, isopropanol) for benchtops and spacecraft materials (Barengoltz, 1997; Benardini et al., 2014; Frick et al., 2014), and Kleenol 30 for the clean room floors (Vaishampayan et al., 2013; Benardini et al., 2014; Mahnert et al., 2015). However, despite these practices, spacecraft assembly facilities possess a persistent, yet low abundant core microbiome $\left(\sim 10^{1}-10^{2}\right.$ colony forming units $(\mathrm{cfu}) / \mathrm{cm}^{2}, \sim 0.2-300$ spores $/ \mathrm{m}^{2}, \sim 1-40 \mathrm{OTU} / \mathrm{m}^{2}$ ), with molecular genetics revealing a taxonomically diverse and dynamic microbial community (Venkateswaran et al., 2001; Moissl et al., 2007; Vaishampayan et al., 2010; La Duc et al., 2012).

Among the more diverse members of this core microbiome are the Acinetobacter, a Gram-negative, nonspore forming, and strictly aerobic genus commonly found in soil and water environments, and increasingly associated with multiantibiotic resistance outbreaks in varying clinical settings (BergogneBérézin et al., 2008). In the context of spacecraft microbiology, nonpathogenic strains of Acinetobacter have been isolated and detected in diverse spacecraft-associated environments, including the surface of the preflight Mars Odyssey orbiter (La Duc et al., 2003), floors in the assembly facility for the Mars Phoenix lander (Ghosh et al., 2010), surfaces in the assembly facilities for the Herschel spacecraft (Moissl-Eichinger et al., 2013), surfaces of the International Space Station (ISS) (Castro et al., 2004), and in the drinking water of the ISS (La Duc et al., 2004). Molecular community analyses further suggest that the diversity (and/or abundance) of Acinetobacter increases during spacecraft assembly, as was observed for the Mars Phoenix lander, where the relative abundance of Acinetobacter among all genera (in operational taxonomic units) increased $\sim 10$-fold upon commencement of assembly and enforcement of the surface and floor cleaning protocols (Vaishampayan et al., 2010).

In fact, for the Mars Phoenix lander, phylogenetic changes across several genera were quantitated over the course of the spacecraft assembly process, which included sampling before, during, and after assembly (Vaishampayan et al., 2010). Together, these net phylogenetic changes (before vs. after assembly) showed (1) relative increases in abundance for the Acinetobacter, Ralstonia, and Brevundimonas (all Gram-negative), (2) relative decreases for Mycoplana, Sphingomonas, and Pseudomonas, and (3) $<1 \%$ or no net changes for most Gram-positive genera such as Streptococcus and the spore-forming Bacillus.

In further detail, and as a comparative example, the Acinetobacter and Streptococcus, respectively, increased $\sim 10$ and $\sim 100$-fold during the assembly process (from $\sim 4 \%$ to $\sim 38 \%$ and from $\sim 0.4 \%$ to $\sim 55 \%$, respectively), likely due to contamination arising from increased personnel and activities within the facilities. However, after assembly, and despite the routine cleaning procedures, the Acinetobacter further increased to $\sim 48 \%$ (or a net $\sim 10$-fold increase) to ultimately represent the numerically dominant genus within the postassembly community. In contrast, the Streptococcus reduced $\sim 180$-fold in abundance and reduced to $0.3 \%$.

These observations of a dynamic and persistent spacecraft microbial community support the hypothesis that the core microbiome is composed of members that harbor a biochemical potential to tolerate the cleaning procedures, and survive the oligotrophic and low-humidity environments of the assembly facilities (La Duc et al., 2007, 2012; MoisslEichinger et al., 2013). Accordingly, the objective of this work was to measure the ability of spacecraft-associated Acinetobacter to metabolize and biodegrade spacecraft cleaning reagents, and survive under extreme conditions, when cultivated under nutrient-restricted conditions.

\section{Materials and Methods}

\subsection{Materials}

Spacecraft-associated Acinetobacter strains were obtained from the Planetary Protection Culture Collection at the Jet Propulsion Laboratory (Pasadena, CA) and included Acinetobacter radioresistens 50v1, Acinetobacter proteolyticus 2P01AA (formerly assigned as Acinetobacter gyllenbergii 2P01AA), Acinetobacter johnsonii 2P08AA, A. johnsonii 2P07AA, Acinetobacter oryzare 2P08MC, Acinetobacter guillouiae 2P07PB, and A. guillouiae 2P07PC. The control type strain, A. radioresistens $43998^{\mathrm{T}}$, was obtained from the American Type Culture Collection.

The spacecraft cleaning reagents of ethanol (Omnipur Pure, 200 proof; VWR), 2-propanol (Fisher Sci.), and Kleenol 30 (Mission Laboratories, Los Angeles, CA; Clovis Janitorial) were sterile filtered, without dilution, and saved as aliquots at $4^{\circ} \mathrm{C}$. Concentrated $5 \times$ minimal medium (M9) was prepared using $64.0 \mathrm{~g} \mathrm{Na}_{2} \mathrm{HPO}_{4} \cdot 7 \mathrm{H}_{2} \mathrm{O}$ (Amresco), $15.0 \mathrm{~g} \mathrm{KH}_{2} \mathrm{PO}_{4}(\mathrm{EM}$ Science), $2.5 \mathrm{~g} \mathrm{NaCl}$ (EM Science), and $5.0 \mathrm{~g} \mathrm{NH}_{4} \mathrm{Cl}$ (EM Science) per liter water. To a $200 \mathrm{~mL}$ aliquot of $5 \times \mathrm{M} 9$ medium, $2.0 \mathrm{~mL}$ of $1 \mathrm{M} \mathrm{MgSO}_{4}$ (EM Science) and $100 \mu \mathrm{L} 1 \mathrm{M} \mathrm{CaCl}_{2}$ (EM Science) were added, and the total solution was diluted to $1 \mathrm{~L}$ using water to yield $1 \times \mathrm{M} 9$; in turn, this medium was further diluted fivefold to yield $0.2 \times \mathrm{M}$ 9. Lysogeny broth (LB) medium was prepared using $10.0 \mathrm{~g}$ tryptone (VWR Amresco), $5.0 \mathrm{~g}$ yeast (Becton, Dickinson and Company), $10.0 \mathrm{~g} \mathrm{NaCl}$ (EM Science), and $1.0 \mathrm{~mL}$ of $1 \mathrm{M} \mathrm{NaOH}$ (Sigma-Aldrich) per liter of water.

Agar plates were prepared using 1 L LB medium and $15 \mathrm{~g}$ of bacteriological agar (AMRESCO). Stock solutions of $10 \mathrm{mM} \mathrm{Fe}{ }^{2+}$ were prepared by fully dissolving $0.19607 \mathrm{~g}$ of $\mathrm{Fe}\left(\mathrm{NH}_{4}\right)_{2}\left(\mathrm{SO}_{4}\right)_{2} \cdot 6 \mathrm{H}_{2} \mathrm{O}$ (EM Science) in $50.0 \mathrm{~mL}$ water, followed by sterile filtration, and storage as aliquots at $4^{\circ} \mathrm{C}$. Buffers included 4-(2-hydroxyethyl)-1-piperazineethanesulfonic acid (HEPES; VWR) and phosphate-buffered saline (PBS, GBiosciences). Temporal changes in cell density were followed by optical density (OD) measurements at $600 \mathrm{~nm}$ (Spectronic 20 Genesys), and by plate counts, which were expressed as $\mathrm{cfu} / \mathrm{mL}$. All microbiology media were autoclaved at $121^{\circ} \mathrm{C}$ for $30 \mathrm{~min}$, buffers and metal solutions were sterile filtered using $0.22 \mu \mathrm{m}$ cellulose acetate filters (VWR), and ultrapure water (18 M $\Omega$ $\mathrm{cm}^{-1}$ ) was used throughout. Solutions of $20 \mathrm{mM}$ nicotinamide adenine dinucleotide $\left(\mathrm{NAD}^{+}\right.$; Sigma-Aldrich) and $10 \mathrm{mM}$ 2,3-bis-(2-methoxy-4-nitro-5-sulfophenyl)-2H-tetrazolium5-carboxanilide (XTT; Amresco) were prepared in water and sterile filtered, where $\mathrm{NAD}^{+}$was stored as aliquots at $-20.0^{\circ} \mathrm{C}$ and XTT was freshly prepared.

\subsection{Ultraminimal cultivations with spacecraft cleaning reagents}

All cultivations were performed in ultraminimal medium

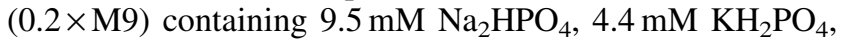
$1.7 \mathrm{mM} \mathrm{NaCl}, 3.7 \mathrm{mM} \mathrm{NH}_{4} \mathrm{Cl}, 0.4 \mathrm{mM} \mathrm{MgSO}_{4}$, and $20 \mu \mathrm{M}$ 
$\mathrm{CaCl}_{2}$. For this study, $0.2 \times \mathrm{M} 9$ was supplemented with $\mathrm{Fe}\left(\mathrm{NH}_{4}\right)_{2}\left(\mathrm{SO}_{4}\right)_{2}$ to provide the sole added transition metal of $26 \mu \mathrm{M} \mathrm{Fe}^{2+}$. Cultivations in this medium were performed using (1) ethanol concentrations ranging from 2 to $650 \mathrm{mM}$, (2) $200 \mathrm{mM}$ mixtures of ethanol and 2-propanol, using the respective mole ratios of $0,0.5,0.85$, and 1 , and (3) mixtures of $16 \mathrm{mM}$ ethanol $(0.1 \% \mathrm{v} / \mathrm{v})$ containing $0.1 \%$ or $1.0 \% \mathrm{v} / \mathrm{v}$ Kleenol 30. Cultivations were also performed using stable isotopes of ethanol, where stationary phase cultures of A. radioresistens 50v1 (OD $\sim 0.9, \sim 9 \times 10^{8} \mathrm{cfu} / \mathrm{mL}$ ) were prepared under ultraminimal conditions $\left(0.2 \times \mathrm{M} 9,26 \mu \mathrm{M} \mathrm{Fe}^{2+}\right)$ using $16 \mathrm{mM}$ ethanol or $\left[1,2-{ }^{13} \mathrm{C}_{2}\right]$ ethanol as the sole carbon source.

All preinoculate cultures were prepared in conditions that matched those of the respective final culture (as already listed), and were inoculated using an isolated colony obtained from LB agar plates, which were prepared from streaks of glycerol stocks of the selected isolate. All preinoculate cultures were 2 or $5 \mathrm{~mL}$ in volume (using $13 \times 100 \mathrm{~mm}$ and $10 \times 1.5 \mathrm{~cm}$ cultures tubes, respectively), agitated at $32^{\circ} \mathrm{C}$ at $200 \mathrm{rpm}$, and grown until mid-log phase (OD $\sim 0.5-0.6$, or $\sim 2 \times 10^{8}-$ $4 \times 10^{8} \mathrm{cfu} / \mathrm{mL}$ ) or late-log phase (OD $\sim 0.6-0.7, \sim 5 \times 10^{8}-$ $\left.7 \times 10^{8} \mathrm{cfu} / \mathrm{mL}\right)$. Fresh medium was inoculated with $1: 100$ volume of the preinoculate, grown at $32^{\circ} \mathrm{C}$ at $200 \mathrm{rpm}$, and treated as described.

Cultivations were performed using capped and parafilmed culture vessels (threaded screw caps for tubes; sterile rubber plugs or aluminum foil for Erlenmeyer flasks). In comparison, cultivations performed in loosely capped culture vessels yielded reliable growth, but irreproducible phenotypic measures, most likely due to evaporation of ethanol. Control experiments included cultures containing all components of the medium except the bacterial inoculum (inoculumnegative) or ethanol carbon source (ethanol-negative); in all cases, the controls yielded no growth.

\subsection{Growth rates and plate counts}

Growth rates were determined by nonlinear regression (KaleidaGraph, Synergy Software; and Microsoft Excel) using a modified version of the Gompertz equation [Eq. (1)] (Begot et al., 1996). Regression parameters included the time of measurement $(t)$, growth rate $(k)$, lag time $(L)$, and the maximum $\log \left(\frac{\Delta O D}{\Delta O D_{\min }}\right)$ value $(A)$. For the regressions, the final OD values for the inoculum-negative controls were negligible, thereby indicating no measurable contamination or formation of nonbiological particulate matter after cultivation.

$$
\begin{aligned}
\log \left(\frac{N}{N_{0}}\right) & =\log \left(\frac{\Delta O D}{\Delta O D_{\min }}\right) \\
& =A \cdot \exp \left(-\exp \left(\frac{k \cdot e}{A} \cdot(L-t)+1\right)\right)
\end{aligned}
$$

For all plate count measurements, aliquots were removed from the cultures, decimally diluted in $0.2 \times \mathrm{M} 9$ (by 10 100,000 -fold), and spread in $20 \mu \mathrm{L}$ aliquots onto LB agar plates. After incubation for $15-24 \mathrm{~h}$ at $32^{\circ} \mathrm{C}$, plates bearing clearly isolated colonies, but no more than $\sim 300$, were enumerated from at least three biological replicates, using at least two technical replicates per trial. For this study, LB agar plates were used for reproducibility purposes, as plating onto M9/ethanol agar plates provided unreliable cell counts (due to inconsistent adsorption of ethanol onto the agar plates across trials, and loss of ethanol and cracking of the agar during incubation). Negligible colony counts were obtained from the inoculum-negative and ethanol-negative controls.

\subsection{Oxidative extremotolerance under ultraminimal conditions}

Cultures $(40 \mathrm{~mL})$ of $A$. radioresistens $50 \mathrm{v} 1$ were prepared in ultraminimal medium $\left(0.2 \times \mathrm{M} 9,26 \mu \mathrm{M} \mathrm{Fe}^{2+}\right)$, containing $16 \mathrm{mM}$ ethanol $(0.1 \% \mathrm{v} / \mathrm{v})$, and exposed to hydrogen peroxide $\left(\mathrm{H}_{2} \mathrm{O}_{2}\right)$. As nutrient-rich controls, cultures $(40 \mathrm{~mL})$ were also prepared in $\mathrm{LB}$ and exposed to $\mathrm{H}_{2} \mathrm{O}_{2}$. All cultures were grown to mid-log phase $\left(\sim 2 \times 10^{8} \mathrm{cfu} / \mathrm{mL}\right.$ in $0.2 \times \mathrm{M} 9 ; \sim 2 \times 10^{9} \mathrm{cfu} /$ $\mathrm{mL}$ in LB), aseptically divided into equal portions, transferred to $250 \mathrm{~mL}$ Erlenmeyer flasks, and treated separately as the respective exposed and unexposed samples.

To the exposed samples, final concentrations of 10, 100, and $400 \mathrm{mM}(0.034 \%, 0.34 \%$, and $1.4 \% \mathrm{w} / \mathrm{v}) \mathrm{H}_{2} \mathrm{O}_{2}$ were added (nonstabilized 30\% w/w; Sigma-Aldrich), and incubated in parallel for $1 \mathrm{~h}$ at $32^{\circ} \mathrm{C}$ with constant agitation at $200 \mathrm{rpm}$. Upon completion, $100 \mu \mathrm{L}$ of the cultures was quenched $1: 10$ with $0.1 \mathrm{mg} / \mathrm{mL}$ bovine liver catalase (to remove any excess $\mathrm{H}_{2} \mathrm{O}_{2}$ ). The exposed and unexposed cultures were then decimally diluted $\left(10^{4}\right.$ - and $10^{5}$-fold dilutions for the $0.2 \times \mathrm{M} 9$ samples, and $10^{6}$-fold dilutions for the LB samples), and $100 \mu \mathrm{L}$ aliquots were spread onto LB agar plates. Plates were incubated and enumerated as described.

\subsection{Alcohol dehydrogenase kinetics}

The kinetics of alcohol dehydrogenase were measured by absorbance spectroscopy (Beckman Coulter DU640). Mid$\log$ phase cultures $(80 \mathrm{~mL})$ of $A$. radioresistens $50 \mathrm{v} 1$ were prepared in $0.2 \times \mathrm{M} 9$ (with $26 \mu \mathrm{M} \mathrm{Fe}^{2+}$ ) containing $16 \mathrm{mM}$ ethanol. Cells were harvested by centrifugation at $6000 \mathrm{~g}$ at $4^{\circ} \mathrm{C}$ for $10 \mathrm{~min}$ (Beckman Coulter Allegra ${ }^{\mathrm{TM}} 21 \mathrm{R}$ ), the supernatants were discarded, and cell pellets thoroughly washed by resuspending in $20 \mathrm{~mL} 1 \times$ PBS, harvesting, and repeating the procedure another two times; at the penultimate step, samples were aliquoted and the final cell pellets stored at $-80^{\circ} \mathrm{C}$.

Protein extracts were prepared from $0.1-0.2 \mathrm{~g}$ of the cell pellets (wet mass), which were thawed on ice, resuspended

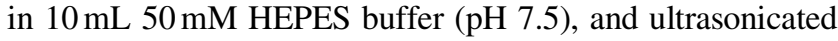
at $30 \mathrm{~s}$ intervals (with $30 \mathrm{~s}$ intervals on ice) for a total of $2 \mathrm{~min}$ of ultrasonication at a power of 5 (Virtis Virsonic Sonicator). The suspensions were then centrifuged at $6000 \mathrm{~g}$ for $20 \mathrm{~min}$ at $4^{\circ} \mathrm{C}$, the supernatants and pellets saved, and independently analyzed for alcohol dehydrogenase activity. Pelleted samples were resuspended in $500 \mu \mathrm{L}$ of $50 \mathrm{mM}$ HEPES $(\mathrm{pH} 7.5)$ containing $1 \%$ Triton X-100 (v/v). All samples were stored on ice and immediately analyzed.

As determined in control experiments, reproducible rates $(n \geq 3)$ were only obtained when simultaneously using $\mathrm{NAD}^{+}$ and an exogenous electron acceptor, such as XTT or DCIP (2,6-dichloroindophenol), with XTT providing lower overall standard deviations. All downstream kinetic studies were performed using $2.5 \mathrm{mM} \mathrm{NAD}^{+}$and $5.0 \mathrm{mM}$ XTT in $50 \mathrm{mM}$ HEPES buffer ( $\mathrm{pH} 7.5$ ), and substrate concentrations of $0.25-$ $10 \mathrm{mM}$ for ethanol or 2-propanol. Reactions were initiated by the addition of $100-200 \mu \mathrm{L}$ sample and followed by monitoring the change in absorbance at $470 \mathrm{~nm}$ every $2 \mathrm{~s}$ for $200-800 \mathrm{~s}$. 
All reactions were thoroughly but gently mixed, $1 \mathrm{~mL}$ in final volume, and performed in $1.0 \mathrm{~mL}$ Plastibrand ${ }^{\circledR}$ disposable UV cuvettes at $22^{\circ} \mathrm{C}$. Reaction rates $(n \geq 3)$ were determined by linear regression over a minimum of 200 s using an $R^{2}$ of $\geq 0.95$, and converted to relevant units using the molar extinction coefficient for XTT $\left(3.70 \times 10^{4} \mathrm{M}^{-1} \mathrm{~cm}^{-1}\right)$. For control purposes, rates of background reduction of XTT by the cellular extracts, in the absence of substrate, were also measured.

Specific activities were expressed as pkat/mg protein $\left(1 \mathrm{pkat}=1 \times 10^{-9}\right.$ katals $=$ conversion of 1 pmole of substrate per second), where protein concentrations of the cell lysates were measured using Bio-Rad standard and DC protein assays following the manufacturer's instructions. MichaelisMenten pseudoparameters were calculated through nonlinear least-squares fitting of the rate data ( $\mathrm{IC}_{50}$ Toolkit; ic50.tk), which provided the parameters of maximum specific activity of catalysis (pkat/mg) and apparent $K_{\mathrm{M}}(\mathrm{mM})$; fits were obtained using aggregated data from several trials $(n=7-9$, ethanol; $n=3-7$, 2-propanol), and standard deviation was calculated from the standard error of the regression.

\subsection{Stable isotope labeling and metabolite profiling}

Stationary phase cultures $(2 \mathrm{~mL})$ of $A$. radioresistens $50 \mathrm{v} 1$ (OD $\sim 0.9, \sim 9 \times 10^{8} \mathrm{cfu} / \mathrm{mL}$ ) were prepared as described using ethanol (natural abundance) or ${ }^{13} \mathrm{C}_{1,2}$-labeled ethanol under ultraminimal conditions $\left(0.2 \times \mathrm{M} 9,26 \mu \mathrm{M} \mathrm{Fe}^{2+}\right)$. All cultures were harvested by centrifugation at $3500 \mathrm{~g}$ for $15 \mathrm{~min}$ at $4^{\circ} \mathrm{C}$ (Beckman Coulter Allegra 21R), the supernatants were discarded, and resulting cell pellets were washed by resuspending in $2-6 \mathrm{~mL} 1 \times \mathrm{PBS}$. The suspensions were centrifuged again, the supernatant was discarded, and washing procedure was repeated once more. The final cell pellets were partly dried by centrifugal evaporation $(\sim 12 \mathrm{~h}$; CentiVap Console), stored at $-80^{\circ} \mathrm{C}$, and ultimately analyzed by untargeted analyses of the primary metabolites by gas chromatography-mass spectrometry (GC-MS).

Cell pellets were extracted by thawing the samples on ice, resuspending in a 50/50 mixture of acetonitrile and water ( $\sim 1.5 \mathrm{~mL} /$ cell pellet), and vortexing for $3-5 \mathrm{~min}$ at a setting of 3000 (Vortex Genie Vortexer 2). Next, samples were clarified by centrifugation $\left(12,000 \mathrm{~g}, 4 \mathrm{~min}, 4^{\circ} \mathrm{C}\right)$, and the supernatants carefully transferred to $2 \mathrm{~mL}$ centrifuge tubes and immediately dried to $\sim 10 \mu \mathrm{L}$ by centrifugal evaporation $(\geq 8 \mathrm{~h}$ at medium heat; DNA 110 Savant DNA SpeedVac). The concentrated extracts were diluted $\sim 100$-fold using $1 \mathrm{~mL}$ of $50 / 50$ acetonitrile $/ \mathrm{H}_{2} \mathrm{O}$, vortexed again, and transferred in $10 \mu \mathrm{L}$ aliquots to microvolume glass inserts (American Chromatography), which had been inserted into $2 \mathrm{~mL}$ centrifuge tubes. Samples were again dried by centrifugal evaporation $(\sim 10 \mathrm{~min}, \mathrm{me}-$ dium heat) and stored at $-80^{\circ} \mathrm{C}$ or immediately prepared for GC-MS analysis.

Samples were derivatized by addition of $10 \mu \mathrm{L}$ of $20 \mathrm{mg} / \mathrm{mL}$ methoxyamine hydrochloride in pyridine (Sigma-Aldrich), followed by incubation at $37^{\circ} \mathrm{C}$ for $90 \mathrm{~min}$. Samples were then equilibrated to room temperature, mixed with $2 \mu \mathrm{L}$ of a standard mixture of fatty acid methyl esters (FAMEs, C8-C10, even chains from C12-C30) (Barding et al., 2013), and silylated by addition of $90 \mu \mathrm{L}$ of $N$-methyl- $N$ (trimethylsilyl)trifluoroacetamide (MSTFA; Sigma-Aldrich) containing $1 \%$ trimethylchlorosilane (Sigma-Aldrich), followed by heating at $37^{\circ} \mathrm{C}$ for $30 \mathrm{~min}$.
Untargeted analyses were also performed on the extracellular fractions of cultures grown in the absence and presence of $0.1 \%$ and $1.0 \%$ (v/v) Kleenol 30. For these samples, late-log cultures $(2 \mathrm{~mL})$ were separated by centrifugation (as described), and the supernatants were removed and separated into $500 \mu \mathrm{L}$ aliquots, dried by centrifugal evaporation, and stored at $-80^{\circ} \mathrm{C}$. Upon analysis, the dried samples were directly derivatized using $90 \mu \mathrm{L}$ MSTFA with $1 \%$ trimethylchlorosilane (with FAMEs standards), followed by heating at $37^{\circ} \mathrm{C}$ for $30 \mathrm{~min}$. All samples were transferred to wide mouth crimp top vials (American Chromatography Supplies, New Jersey) and sealed with an $11 \mathrm{~mm}$ crimp cap. Samples were analyzed by GC-MS within $24 \mathrm{~h}$ of derivatization.

All samples were analyzed on an Agilent Technologies 6890N Network GC System connected to an Agilent Technologies 5973 Inert Mass Selective Detector and outfitted with a 7683B Series Injector. Separations were performed using an Agilent J\&WDB-5ms GC-capillary column $(30 \mathrm{~m} \times 0.25 \mathrm{~mm}$ i.d.) and an integrated $10 \mathrm{~m}$ guard column. Samples $(1 \mu \mathrm{L})$ were introduced by splitless injection using a constant helium gas $(99.999 \%$ purity) flow of $1 \mathrm{~mL} / \mathrm{min}$. Injection port temperature was maintained at $250^{\circ} \mathrm{C}$, and the separation was performed using an initial oven temperature of $60^{\circ} \mathrm{C}$ (for $1 \mathrm{~min}$ ) and a temperature ramp of $10^{\circ} \mathrm{C} / \mathrm{min}$ to $320^{\circ} \mathrm{C}$ (hold for $5 \mathrm{~min}$ ). Mass spectra were obtained by electron impact ionization at $70 \mathrm{eV}$, using an ion source temperature of $230^{\circ} \mathrm{C}$ and collected over a mass range of $60-600 \mathrm{~m} / \mathrm{z}(2.71 \mathrm{scans} / \mathrm{s})$.

Deconvolution and identification were performed on the raw data using the Automated Mass Spectral Deconvolution and Identification System software (AMDIS, National Institute of Standards and Technology) using a retention index of $\pm 2 \%$ and a corrected match factor of at least 700 . The data were integrated using Agilent Mass Hunter Quantitative Analysis B.07.00M after translation with the GC MSD Translator (Agilent). Analyte abundances were compared using parametric $t$-tests, and multiple hypothesis testing was corrected for using a Benjamini-Hochberg false discovery rate of 0.10 (Microsoft Excel).

\section{Results}

\subsection{Cultivations under ultraminimal conditions}

Growth rates and viability were measured for multiple spacecraft-associated Acinetobacter strains under ultraminimal conditions $\left(0.2 \times \mathrm{M} 9,16 \mathrm{mM}\right.$ ethanol, $\left.26 \mu \mathrm{M} \mathrm{Fe}^{2+}\right)$. The tested strains included $A$. radioresistens $50 \mathrm{v} 1$, which was isolated from the surface of the preflight Mars Odyssey orbiter, and A. proteolyticus 2P01AA, A. johnsonii 2P08AA, A. johnsonii 2P07AA, A. oryzare 2P08MC, A. guillouiae 2P07PB, and A. guillouiae 2P07PC, which were isolated from the floor of the assembly facility for the Mars Phoenix lander. As shown in Figure 1A and Supplementary Fig. S1 (see Supplementary Data at https://www.liebertpub.com/suppl/doi/10.1089/ast .2017.1814), except for the 2P01AA strain, all spacecraftassociated Acinetobacter strains grew on ethanol as the sole carbon source, with growth rates ranging from $\sim 0.36$ to $0.53 \mathrm{~h}^{-1}$ (in $16 \mathrm{mM}$ or $0.1 \% \mathrm{v} / \mathrm{v}$ ethanol), where the fastest rates were exhibited by A. johnsonii 2P08AA $\left(0.53 \pm 0.03 \mathrm{~h}^{-1}\right)$.

At 10 -fold higher concentrations of ethanol $(160 \mathrm{mM}$ or $1.0 \% \mathrm{v} / \mathrm{v})$, rates for the $2 \mathrm{P} 08 \mathrm{AA}$ and $2 \mathrm{P} 07 \mathrm{AA}$ strains were $\sim 1.5$-fold lower $(p<0.05)$, whereas rates for the $50 \mathrm{v} 1$, 

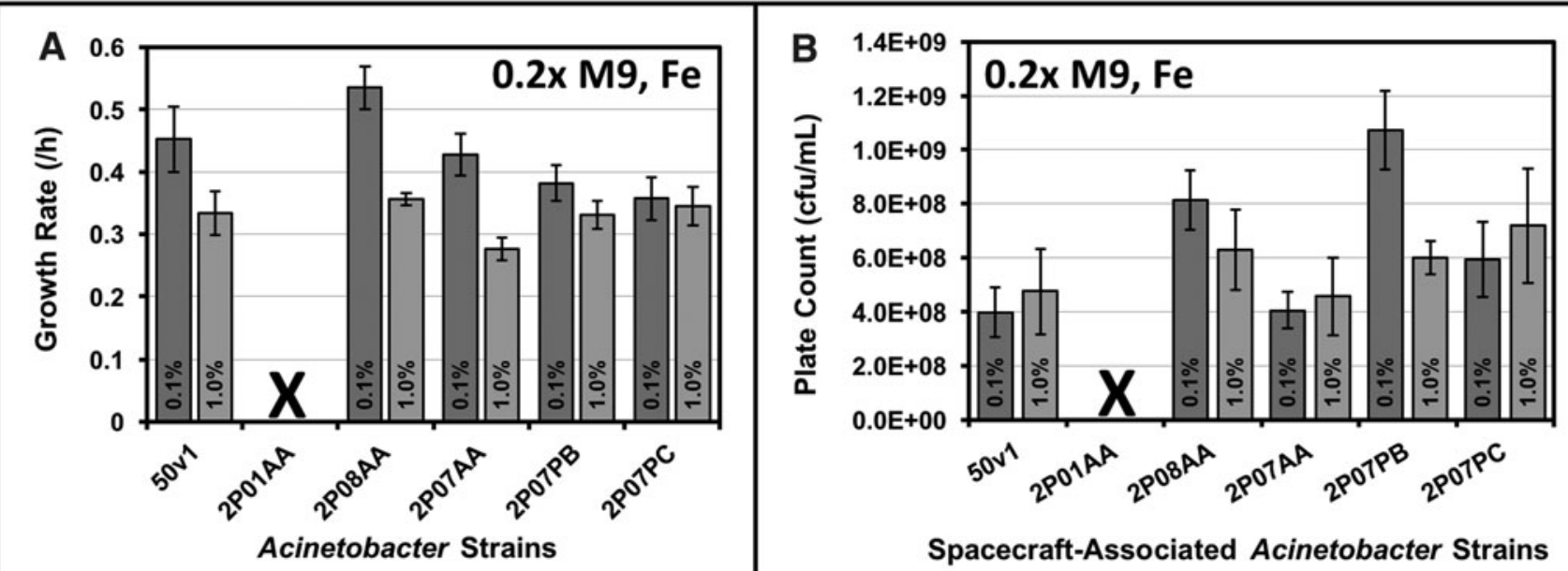

Spacecraft-Associated Acinetobacter Strains

FIG. 1. (A) Growth rates and (B) mid-log phase plate counts for differing strains of spacecraft-associated Acinetobacter (50v1, 2P01AA, 2P08AA, 2P07AA, 2P07PB, and 2P07PC) cultivated in $0.2 \times \mathrm{M} 9\left(32^{\circ} \mathrm{C}\right)$ containing $26 \mu \mathrm{M} \mathrm{Fe}{ }^{2+}$ and $16 \mathrm{mM}$ $(0.1 \% \mathrm{v} / \mathrm{v})$ or $160 \mathrm{mM}(1.0 \% \mathrm{v} / \mathrm{v})$ ethanol; the respective growth curves are provided in Supplementary Figure S1 (X demarks no measurable growth, $n=6-7$, errors bars in (A) represent the standard error of regression and in (B) the standard deviation).

2P07PB, and 2P07PC strains were, respectively, and statistically equivalent across 16 and $160 \mathrm{mM}$ ethanol. As displayed in Figure 1B, viable cultures were confirmed by plate counts on mid-log phase cultures, which provided cell densities ranging from $\sim 4 \times 10^{8}$ to $1 \times 10^{9} \mathrm{cfu} / \mathrm{mL}$. Most strains displayed similar cell densities when grown on 16 or $160 \mathrm{mM}$ ethanol; however, plate counts for the $2 \mathrm{P} 07 \mathrm{~PB}$ strain were $\sim 1.8$-fold higher $\left(1.1 \times 10^{9} \pm 1.5 \times 10^{8} \mathrm{cfu} / \mathrm{mL}\right)$ in $16 \mathrm{mM}$ ethanol.

As a species-level comparison, growth rates were also measured across a range of ethanol concentrations $(2-650 \mathrm{mM})$ for $A$. radioresistens $50 \mathrm{v} 1$ and $A$. radioresistens $43998^{\mathrm{T}}$, which served as a nonspacecraft-associated control for this study (Fig. 2A). For the 50v1 strain, rates were fastest at $8 \mathrm{mM}$ ethanol $\left(0.46 \pm 0.02 \mathrm{~h}^{-1}\right)$ and gradually trended downward between 40 and $650 \mathrm{mM}$ (from $0.43 \pm 0.04$ to $0.11 \pm 0.02 \mathrm{~h}^{-1}$ ). For the type strain, growth rates were essentially equivalent across the range of tested ethanol concentrations; overall, the rates $\left(\sim 0.22 \mathrm{~h}^{-1}\right)$ between $\sim 2$ and $40 \mathrm{mM}$ ethanol were $\sim 2$-fold lower than those of the 50v1 strain. For both strains, growth at concentrations $<2 \mathrm{mM}$ provided irreproducible results.

For the 50v1 strain, cultivations were also performed in mixtures of ethanol and 2-propanol using the mole ratios of 0 , $0.15,0.50,0.85$, and 1.0 , at a final concentration of $200 \mathrm{mM}$ (Fig. 2B). Using these mixtures, reproducible growth rates and high plate counts $\left(\sim 10^{8} \mathrm{cfu} / \mathrm{mL}\right)$ were obtained at mole ratios of $0.15,0.50$, and 0.85 . For instance, cultures grown in mixtures of $170 \mathrm{mM}$ ethanol and $30 \mathrm{mM}$ 2-propanol (mole fraction of 0.15$), 100 \mathrm{mM}$ ethanol and $100 \mathrm{mM}$ 2-propanol (mole fraction of 0.50 ), and $30 \mathrm{mM}$ ethanol and $170 \mathrm{mM} \mathrm{2-}$ propanol (mole fraction of 0.85 ) exhibited mid-log phase

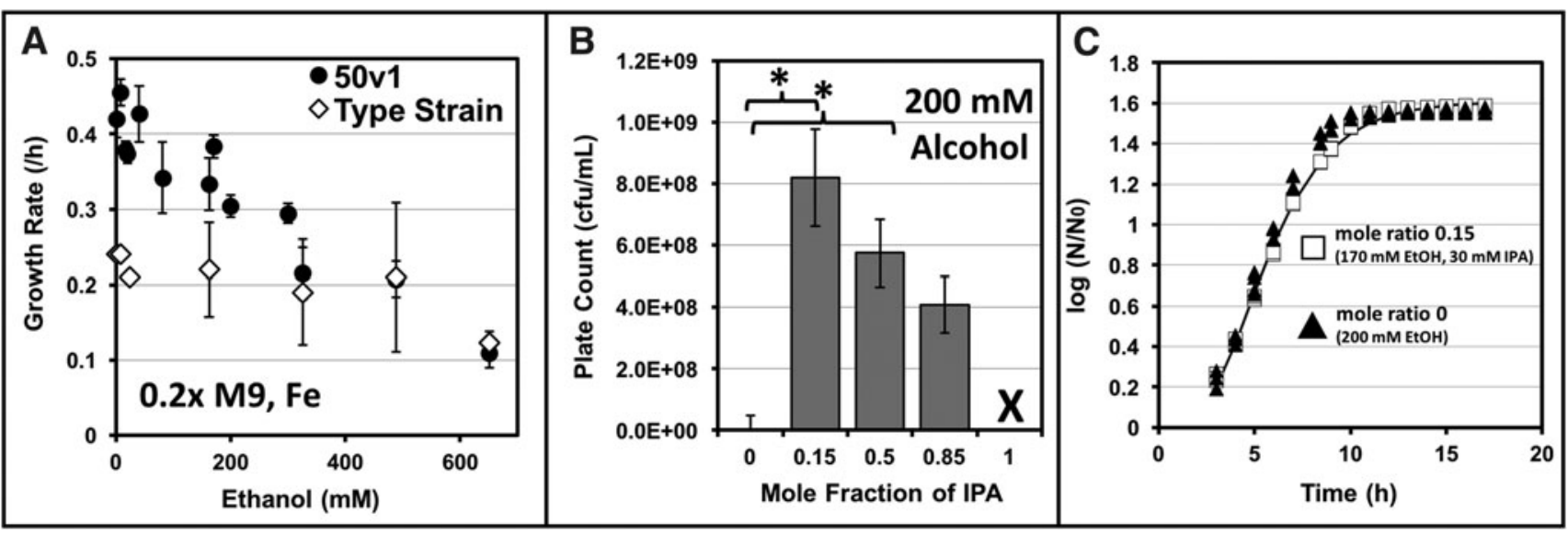

FIG. 2. (A) Growth rates of Acinetobacter radioresistens $50 \mathrm{v} 1$ and A. radioresistens $43998^{\mathrm{T}}$ cultivated $\left(32^{\circ} \mathrm{C}\right)$ in $0.2 \times \mathrm{M} 9$ and $26 \mu \mathrm{M} \mathrm{Fe}^{2+}$ containing $2-650 \mathrm{mM}$ ethanol $(n=2-6$, errors bars represent the standard error of regression); (B) mid-log phase plate counts of $A$. radioresistens $50 \mathrm{v} 1$ obtained from cultivations $\left(32^{\circ} \mathrm{C}\right)$ in $0.2 \times \mathrm{M} 9$ and $26 \mu \mathrm{M} \mathrm{Fe}{ }^{2+}$ containing $200 \mathrm{mM}$ ethanol (mole ratio 0), $170 \mathrm{mM}$ ethanol, and $30 \mathrm{mM}$ 2-propanol (mole ratio 0.15), $100 \mathrm{mM}$ ethanol and $100 \mathrm{mM} 2-$ propanol (mole ratio 0.50), $30 \mathrm{mM}$ ethanol and $170 \mathrm{mM}$ 2-propanol (mole ratio 0.85), and $200 \mathrm{mM} 2$-propanol (mole ratio 1.0) (*demarks statistical significance of $p<0.05, \mathrm{X}$ demarks no growth, $n=5-11$, and error bars represent the standard deviation); and $(\mathbf{C})$ growth rates of A. radioresistens $50 \mathrm{v} 1$ cultivated $\left(32^{\circ} \mathrm{C}\right)$ in $0.2 \times \mathrm{M} 9$ and $26 \mu \mathrm{M} \mathrm{Fe}{ }^{2+}$ containing $200 \mathrm{mM}$ ethanol (mole ratio 0; triangles) or $170 \mathrm{mM}$ ethanol and $30 \mathrm{mM}$ 2-propanol (mole ratio 0.15; squares). 
plate counts of $8.2 \times 10^{8} \pm 1.6 \times 10^{8}, 5.8 \times 10^{8} \pm 1.1 \times 10^{8}$, and $4.1 \times 10^{8} \pm 0.9 \times 10^{8} \mathrm{cfu} / \mathrm{mL}$, respectively.

Comparison of the plate counts $(p<0.05)$ revealed that cell densities obtained at a mole ratio of 0.15 (170/30 ethanol/ 2-propanol) were $\sim 2$-fold higher than those obtained at $200 \mathrm{mM}$ ethanol (mole ratio of $0 ; 4.0 \times 10^{8} \pm 0.5 \times 10^{8} \mathrm{cfu} / \mathrm{mL}$ ), and $\sim 1.7$-fold higher than those obtained (in control experiments) at $170 \mathrm{mM}$ ethanol $\left(4.7 \times 10^{8} \pm 1.6 \times 10^{8} \mathrm{cfu} / \mathrm{mL}\right)$. In contrast, growth rates at the respective mole ratios of 0.15 and 0 (as measured through OD) were statistically equivalent, amounting to $0.33 \pm 0.04$ and $0.30 \pm 0.01 \mathrm{~h}^{-1}$ (Fig. 2C). Furthermore, at a mole ratio of 0.50 , and when compared with the $200 \mathrm{mM}$ ethanol control, the plate counts were $\sim 1.5$-fold higher $(p<0.05)$, and the growth rate was $\sim 1.3$-fold lower $\left(0.25 \pm 0.01 \mathrm{~h}^{-1}\right)$. Finally, at a mole ratio of 0.85 , and when compared with the $200 \mathrm{mM}$ ethanol control, the plate counts were statistically equivalent, while the growth rate was $\sim 1.5$ fold lower $\left(0.21 \pm 0.02 \mathrm{~h}^{-1}\right)$.

Together, these trends indicated that cell viabilities at mid$\log$ phase were maximally enhanced in the presence of low mole ratios of 2-propanol, and that a concentration of $30 \mathrm{mM} 2-$ propanol was not inhibitory, as the growth rate was unaffected. At a higher mole ratio of 0.85 , however, longer cultivation times were required to reach mid-log phase, as indicated by the slower growth rates (in $170 \mathrm{mM} 2$-propanol), and cell viabilities at mid-log phase were not enhanced. Unsurprisingly, no growth was observed under these conditions when using 2propanol as a sole carbon source (mole ratio of 1.0).

\subsection{Oxidative extremotolerance under ultraminimal conditions}

The extremotolerance of A. radioresistens 50v1 toward aqueous hydrogen peroxide $\left(\mathrm{H}_{2} \mathrm{O}_{2}\right)$ was measured in both nutrient-rich $(\mathrm{LB})$ and ultraminimal $(0.2 \times \mathrm{M} 9,16 \mathrm{mM}$ ethanol, $\left.26 \mu \mathrm{M} \mathrm{Fe}^{2+}\right)$ media. For mid-log phase cultures $\left(1.5 \times 10^{8} \pm 0.4 \times 10^{8} \mathrm{cfu} / \mathrm{mL}\right.$ ), exposures of $10 \mathrm{mM} \mathrm{H}_{2} \mathrm{O}_{2}$ (for $1 \mathrm{~h}$ ) in ultraminimal medium resulted in a $\sim 1.5-\log$ reduction in survival $\left(5.3 \times 10^{6} \pm 2.4 \times 10^{6} \mathrm{cfu} / \mathrm{mL}\right)$. In sharp contrast, exposures to mid-log phase cultures in nutrient-rich medium resulted in no loss in survival $\left(1.9 \times 10^{9} \pm 0.4 \times 10^{9} \mathrm{cfu} / \mathrm{mL}\right.$, $10 \mathrm{mM} \mathrm{H}_{2} \mathrm{O}_{2}, 1 \mathrm{~h}$ ). Furthermore, at $100 \mathrm{mM} \mathrm{H}_{2} \mathrm{O}_{2}$, no viability was observed in ultraminimal medium; whereas only a $\sim 1-\log$ reduction was measured in nutrient-rich medium $\left(3.0 \times 10^{8} \pm 0.4 \times 10^{8} \mathrm{cfu} / \mathrm{mL}\right)$. These results revealed a positive correlation between nutrient availability and survivability, as (expectedly) oxidative extremotolerance was significantly enhanced under nutrient-rich conditions. However, exposures to $10 \mathrm{mM} \mathrm{H}_{2} \mathrm{O}_{2}$ in ultraminimal medium resulted in appreciable survivals, as exposures to $\sim 5 \times 10^{6}$ cfu/mL yielded only an $\sim 30$-fold loss in viability.

\subsection{Stable isotope labeling}

Cultivation on ethanol as a sole carbon source was confirmed by untargeted metabolomics analysis and stable isotope profiling using ${ }^{13} \mathrm{C}$-labeled ethanol $\left(\left[1,2-{ }^{13} \mathrm{C}_{2}\right]-\right.$ ethanol). Cultures of $A$. radioresistens 50v1 were prepared in ultraminimal medium $\left(0.2 \times \mathrm{M} 9,26 \mu \mathrm{M} \mathrm{Fe}{ }^{2+}\right)$ using $16 \mathrm{mM}$ ethanol or ${ }^{13} \mathrm{C}$-labeled ethanol, and the cell extracts were analyzed by GC-MS (Supplementary Fig. S2A, B).

As listed in Supplementary Table S1, cultivations on ethanol in ultraminimal medium yielded an array of metabolites, including citric acid cycle intermediates (malate and citrate), mono and disaccharides (fructose, glucose, and trehalose), amino acids (asp, cys, glu, gln, gly, ile, lys, met, phe, pro, ser, thr, trp, tyr, and val), modified amino acids (2-oxoproline, homoserine, ornithine, and $\beta$-alanine), peptides (glycylglycine), short and long chain fatty acids (11-octadecenoic acid, 2-butenedioic acid, 2-hexenedioic acid, 2-propenoic acid, 9octadecenoic acid, butanedioic acid, hydroxybutyric acid, myristic acid, nonanoic acid, palmitic acid, pentanedioic acid, propanoic acid, and stearic acid), fatty alcohols (1-hexadecanol, 1-octadecanol, 2-dodecanol), nucleobases (adenine and pyrimidine), and a variety of other metabolites (e.g., 3-amino-2piperidone, 3-hydroxyisovaleric acid, 4-hydroxybenzoic acid, 4-hydroxyphenyllactic acid, benzenepropanoic acid, dimethyl tartarate, homogentisic acid, indole-2-carboxylic acid, $\mathrm{N}$ ethyldiethanolamine, and oxalic acid).

Confirmation of ethanol incorporation was obtained by comparison of these metabolites with those extracted from cells cultivated on ${ }^{13} \mathrm{C}$-labeled ethanol. As representative examples, mass spectra for oleic acid [(E)-9-octadecenoic acid] and trehalose ( $\alpha$-D-glucopyranosyl- $(1 \leftrightarrow 1)-\alpha$-D-glucopyranose) are provided in Figure 3. In Figure 3A (highlighted by the arrow), the molecular ion for the MSTFA-derivatized version of oleic acid (trimethylsilyl ester of oleic acid, $354.6 \mathrm{~g} / \mathrm{mol}$ ) is observed at a mass-to-charge ratio $(\mathrm{m} / \mathrm{z})$ of 354 . In comparison, mass spectra for oleic acid obtained from cultures grown on ${ }^{13} \mathrm{C}$ labeled ethanol yielded a molecular ion at $372 \mathrm{~m} / \mathrm{z}$, representing a gain of 18 mass units, consistent with ${ }^{13} \mathrm{C}$ incorporation at each of the 18 carbons of oleic acid $\left(18: 1^{\Delta 9}\right)$. For trehalose, in Figure 3B, the fragment ion at $361 \mathrm{~m} / \mathrm{z}$ represented a six-carbon product resulting from scission at the glycosidic bond to yield two identical fragment ions (Füzfai et al., 2008). In comparison, mass spectra of trehalose obtained from cultures grown on ${ }^{13} \mathrm{C}$-labeled ethanol yielded a fragment ion peak at $367 \mathrm{~m} / \mathrm{z}$, representing a gain of 6 mass units, consistent with ${ }^{13} \mathrm{C}$ incorporation at each of the carbons in the fragment ions.

\subsection{Kinetics of ethanol and 2-propanol oxidation}

The alcohol dehydrogenase activities in cellular extracts of A. radioresistens 50v1 were measured against the substrates of ethanol and 2-propanol (Fig. 4). Cultures were prepared under ultraminimal conditions $\left(0.2 \times \mathrm{M} 9,26 \mu \mathrm{M} \mathrm{Fe}^{2+}\right)$ using $16 \mathrm{mM}$ ethanol as the sole carbon source. Extracts were prepared by ultrasonication, and the membrane (resuspended pellet) and soluble (supernatant) fractions were separately tested for alcohol oxidation activities. Comparisons of the protein extracts revealed approximately fivefold higher specific activities in the membrane fractions. Kinetic studies on the membrane fractions using the substrates of ethanol or 2-propanol (Fig. 4A, B) revealed standard Michaelis-Mententype behavior, with nonlinear regressions providing maximum specific activities of $23 \pm 3 \mathrm{pkat} / \mathrm{mg}$ and $1.4 \pm 0.4 \mathrm{pkat} /$ mg (and apparent $K_{\mathrm{M}}$ values of $\sim 0.3$ and $\sim 0.4 \mathrm{mM}$ ), respectively. As shown in Figure 4C, the calculated maximum specific activities for ethanol were $\sim 16$-fold higher than that of 2-propanol.

\subsection{Biodegradation of Kleenol 30}

The biodegradation of Kleenol 30 was measured in cultures of A. radioresistens $50 \mathrm{v} 1$ prepared in ultraminimal medium $\left(0.2 \times \mathrm{M} 9,26 \mu \mathrm{M} \mathrm{Fe}^{2+}\right)$ containing $16 \mathrm{mM}$ ethanol 


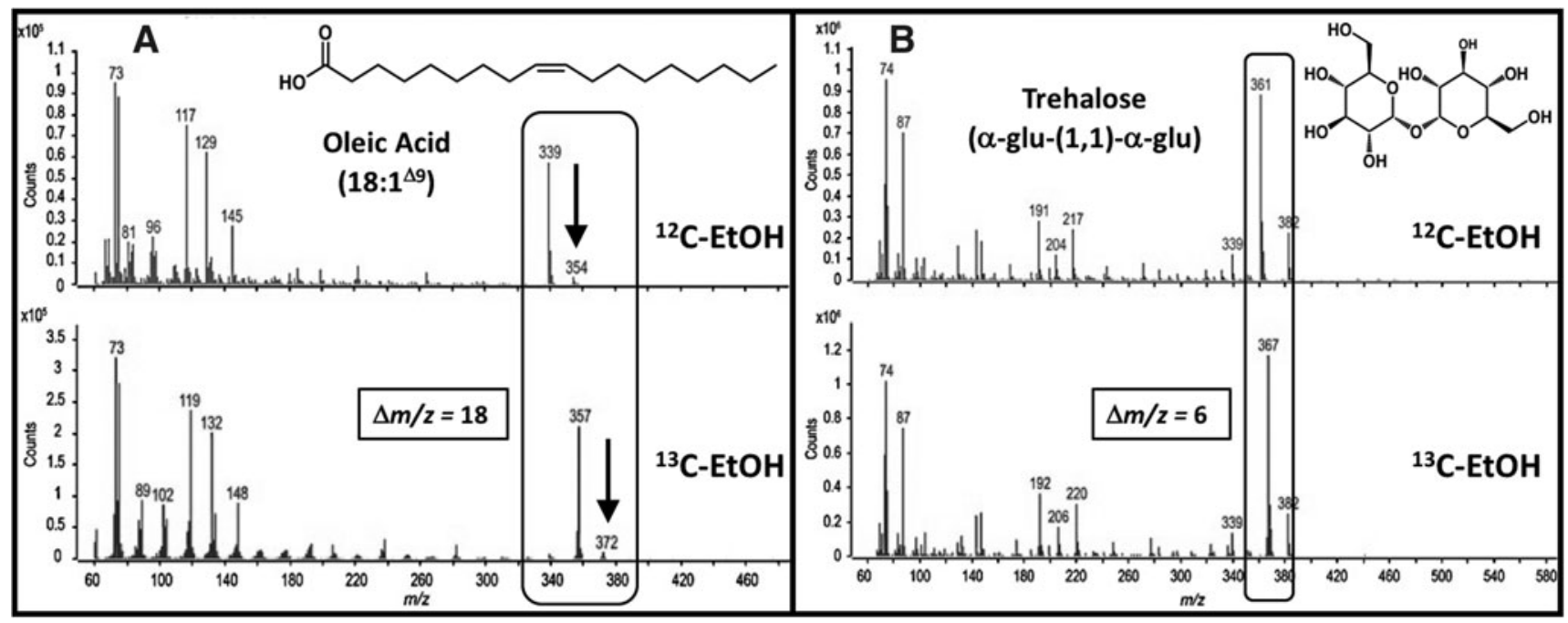

FIG. 3. Mass spectra for (A) oleic acid $\left(18: 1^{\Delta 9}\right)$ and (B) trehalose [ $\alpha$-D-glucopyranosyl-(1 $\left.\leftrightarrow 1\right)-\alpha$-D-glucopyranose] extracted from cultures of $A$. radioresistens $50 \mathrm{v} 1$ cultivated $\left(32^{\circ} \mathrm{C}\right)$ in $0.2 \times \mathrm{M} 9$ and $26 \mu \mathrm{M} \mathrm{Fe} \mathrm{F}^{2+}$ containing $16 \mathrm{mM}$ $\left[1,2-{ }^{13} \mathrm{C}_{2}\right]$ ethanol; inset structures represent the underivatized compound, rounded corner boxes highlight the molecular ion (arrow) or fragment ion, and the representative total ion chromatogram is provided in Supplementary Figures S2A and S2B.

with $0.1 \%$ or $1.0 \% \mathrm{v} / \mathrm{v}$ Kleenol 30 . Growth rates in the presence of $0.1 \% \mathrm{v} / \mathrm{v}$ Kleenol 30 were not impacted $\left(0.46 \pm 0.03 \mathrm{~h}^{-1}\right)$ when compared with parallel cultures grown in absence of Kleenol $30\left(0.48 \pm 0.02 \mathrm{~h}^{-1}\right)$; however, growth rates decreased $\sim 1$. -fold in $1.0 \% \mathrm{v} / \mathrm{v}$ Kleenol 30 $\left(0.41 \pm 0.02 \mathrm{~h}^{-1}\right)$. For all cultures, clarified media (or the extracellular fraction) were prepared by centrifugation and analyzed by GC-MS, and relevant controls included cultures of the (1) 50v1 strain containing no Kleenol 30 and (2) Kleenol 30 incubated for equivalent times in $0.2 \times \mathrm{M} 9$ containing $26 \mu \mathrm{M} \mathrm{Fe}^{2+}, 16 \mathrm{mM}$ ethanol, and no bacteria (Supplementary Fig. S2D, E).

Comparison of the data $(p<0.0171, t$-test, false discovery rate of 0.10 ) supported the formation of degradation products,

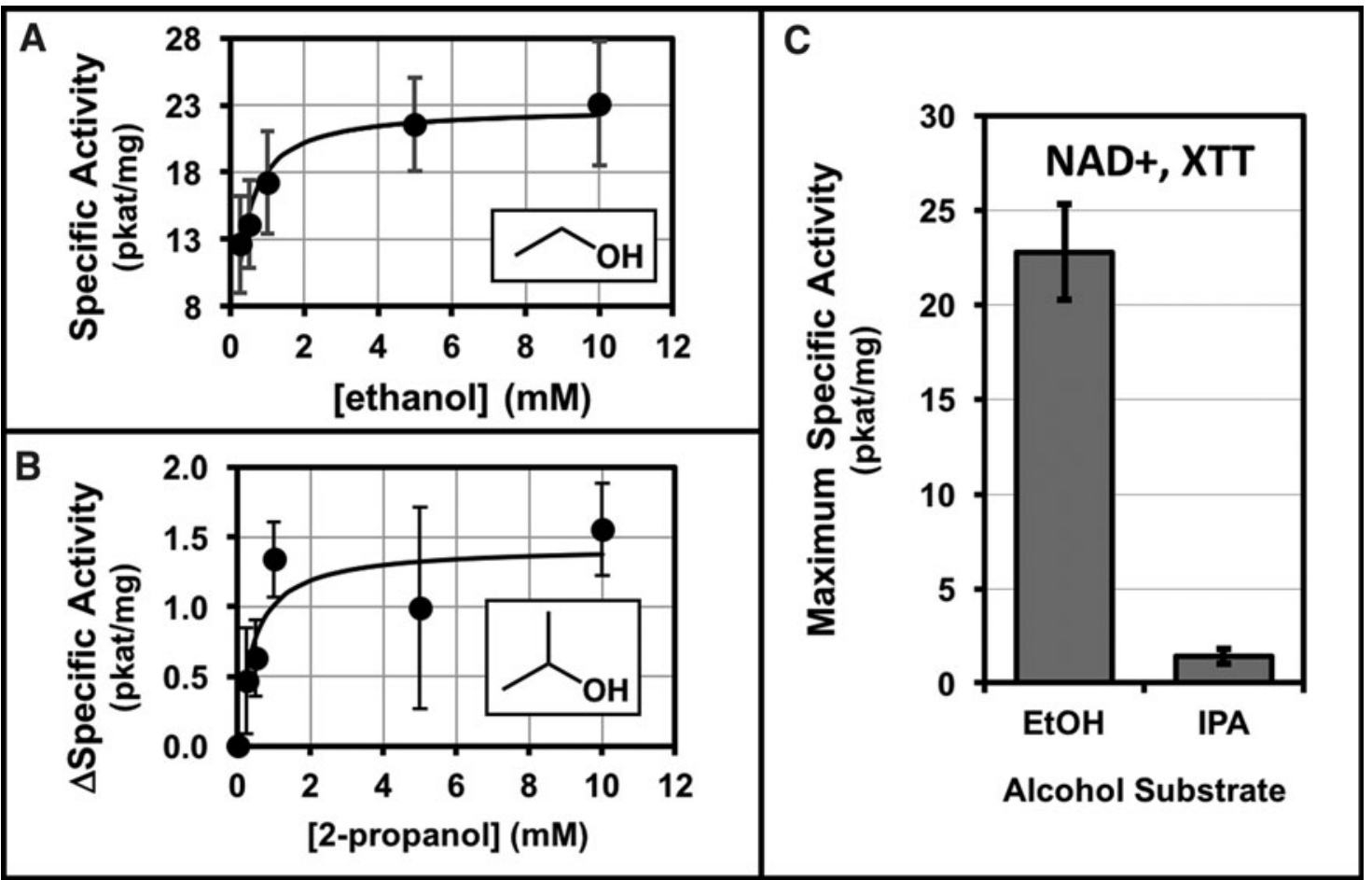

FIG. 4. Michaelis-Menten kinetics and nonlinear least-squares regressions (fitted line) for (A) ethanol and (B) 2-propanol catalysis using suspended membrane fractions of $A$. radioresistens $50 \mathrm{v} 1$ (cultivated in $0.2 \times \mathrm{M} 9,26 \mu \mathrm{M} \mathrm{Fe}$, and $16 \mathrm{mM}$ ethanol at $32^{\circ} \mathrm{C}$ ), and $(\mathbf{C})$ comparisons of the maximum specific activities (pkat/mg) for ethanol and 2-propanol (error bars represent the standard deviation, $n=7-9$ for ethanol and $n=3-7$ for 2-propanol). 


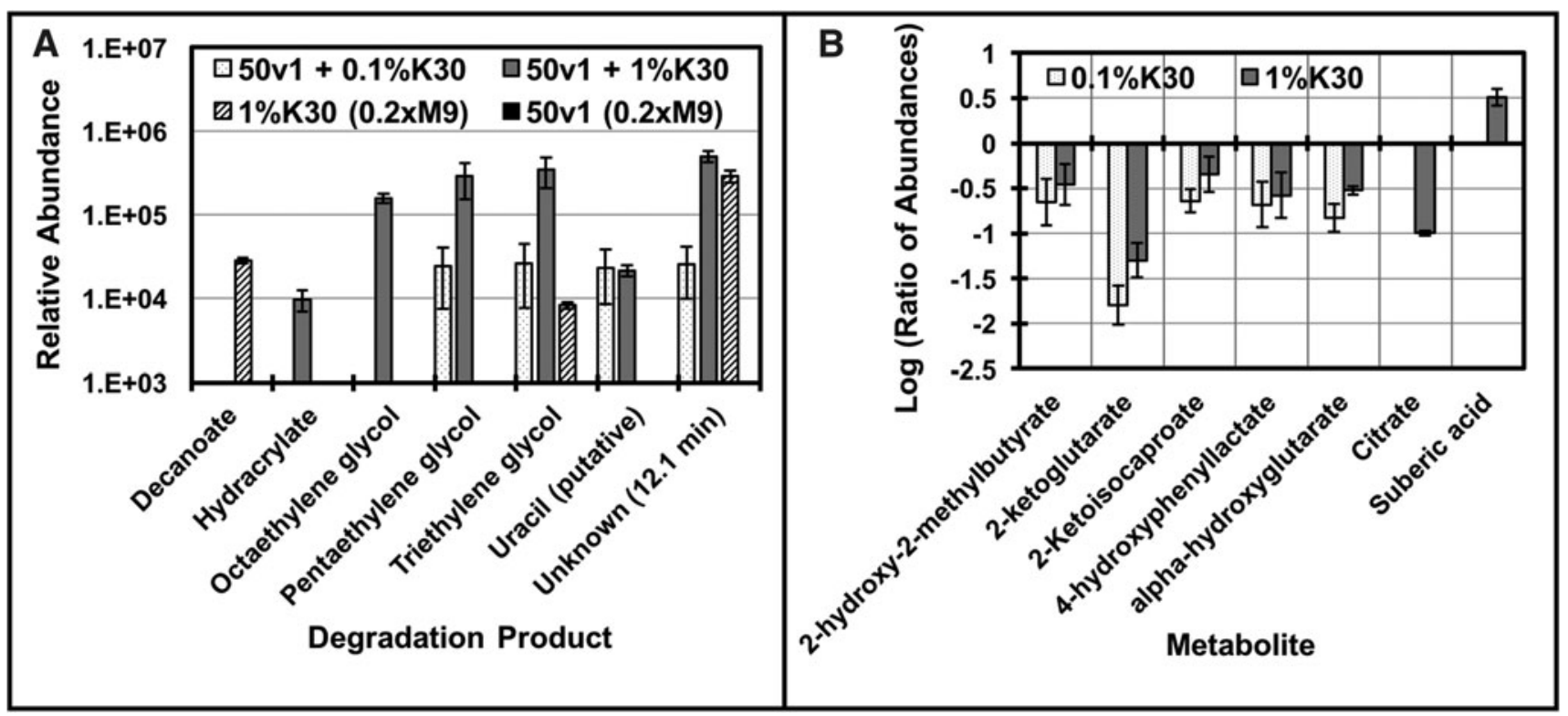

FIG. 5. Biodegradation and impacts of $0.1 \%$ and $1.0 \% \mathrm{v} / \mathrm{v}$ Kleenol 30 on cultures of A. radioresistens $50 \mathrm{v} 1(0.2 \times \mathrm{M} 9$, $26 \mu \mathrm{M} \mathrm{Fe}^{2+}, 16 \mathrm{mM}$ ethanol, $32^{\circ} \mathrm{C}$ ), where $(\mathbf{A})$ the relative abundances of the degradation products for Kleenol 30 (K30) are compared with those in the control samples of (1) K30 incubated in $0.2 \times \mathrm{M} 9(1 \% \mathrm{~K} 30)$ and (2) the 50v1 strain grown in the absence of K30 (50v1 $0.2 \times \mathrm{M} 9$ ); (B) impacts on the extracellular metabolites, as displayed by the logarithm of the ratio of abundances measured in the presence of $\mathrm{K} 30(0.1 \%$ and $1.0 \%)$ and absence of $\mathrm{K} 30(50 \mathrm{v} 10.2 \times \mathrm{M} 9$, control sample $)$, where negative values indicated a decrease in abundance compared with the control, and positive values indicated an increase in abundance compared with the control (for these experiments, biological replicates referred to samples cultivated from plates prepared from glycerol stocks, and technical replicates referred to samples cultivated from separate colonies from the same plate; all metabolites were detected in three biological replicates $[n=3]$, with at least one technical replicate per condition, except for citrate [ $n=1$ with three technical replicates] and suberic acid $[n=1$ with two technical replicates]; error bars represent $(\mathbf{A})$ the standard deviation and $(\mathbf{B})$ propagated error).

impacts to the extracellular metabolome, and potential metabolism of a component of Kleenol 30 (Fig. 5). As summarized in Figure 5A, compounds (retention time [RT], min) including hydracrylate (RT 8.2), octaethylene glycol (RT 25.0), pentaethylene glycol (RT 18.6), triethylene glycol (RT 16.0), and uracil (putative assignment, RT 10.8) were only detected in the presence of Kleenol 30 and A. radioresistens $50 \mathrm{v} 1$. In comparison, these compounds were undetectable (or below the limit of detection) in the control samples. Together, this directly supported biodegradation of Kleenol 30 (presumably a polymeric ethylene glycol formulation) into lower molecular weight and volatilizable constituents. In context, the known components of Kleenol 30 (http://hazard.com/msds/f2/byw/bywhr.html) include $12.5 \%$ ethylene glycol monobutyl ether, 1-5\% nonylphenol ethoxylate, $1 \%$ dodecylbenzenesulfonate, and $1-4 \%$ silicic acid, disodium salt.

As summarized in Figure 5B, impacts to the extracellular metabolome were supported by decreases in abundances for several hydroxy- and ketoacids, including 2-ketoglutarate, $\alpha$-hydroxyglutarate, 2-ketoisocaproate, citrate, and 4-hydroxyphenyllactate. Furthermore, control experiments with Kleenol 30 (Fig. 5A) showed that incubations in $0.2 \times \mathrm{M} 9$ (containing $26 \mu \mathrm{M} \mathrm{Fe}^{2+}$ and $16 \mathrm{mM}$ ethanol), in the absence of $A$. radioresistens $50 \mathrm{v} 1$, yielded substantial increases in the abundances of decanoate (10:0). However, in the presence of A. radioresistens $50 \mathrm{v} 1$, decanoate was not detected, suggesting either biodegradation or metabolism of this product.

\section{Discussion}

In this study, we measured the ability of several strains of spacecraft-associated Acinetobacter to metabolize or biodegrade the reagents used to clean spacecraft, and surfaces and floors of spacecraft assembly facilities. Cultivations in the presence of the cleaning reagents were conducted under ultraminimal conditions to roughly approximate the lownutrient and low-particulate (inorganics and organics) conditions of the assembly facilities. Cultivations were performed in $0.2 \times \mathrm{M} 9$ minimal medium supplemented with $26 \mu \mathrm{M} \mathrm{Fe}^{2+}$, where alkali, halogen, and main group elements (i.e., N, S, and P, excluding oxygen) were $<15 \mathrm{mM}$ in concentration, alkaline earth metals were $\leq 0.4 \mu \mathrm{M}$, and heavy metals contaminants were collectively $\leq 0.001 \%$ of the medium constituents. In comparison with prior work, early cultivations of the Acinetobacter on ethanol relied upon inorganic-rich medium (Abbott et al., 1973) containing a variety of supplemented metalloids and transition metals (e.g., 0.1-100 $\mu \mathrm{M}$ concentrations of $\mathrm{Fe}, \mathrm{Mn}, \mathrm{Cu}, \mathrm{Co}, \mathrm{Zn}, \mathrm{Mo}$, and B), with other media containing organic components such as citrate (Du Preez et al., 1981), and yeast autolysate and pantothenate (Pirog and Kuz'minskaya, 2003).

Under more extreme nutrient-restricted conditions $(0.2 \times \mathrm{M} 9$, $\left.26 \mu \mathrm{M} \mathrm{Fe}^{2+}\right)$, most of the tested spacecraft-associated strains grew on ethanol as a sole carbon source (six out of the seven tested strains). Cultivations provided high cell counts at midlog phase $\left(10^{8}-10^{9} \mathrm{cfu} / \mathrm{mL}\right.$ ), where generation times (or doubling times) ranged from 0.56 to $0.80 \mathrm{~h}$ in $16 \mathrm{mM}(0.1 \%$ 
$\mathrm{v} / \mathrm{v})$ ethanol, and from 0.85 to $1.1 \mathrm{~h}$ in $160 \mathrm{mM}(1.0 \% \mathrm{v} / \mathrm{v})$ ethanol. All viable spacecraft-associated strains grew optimally at lower ethanol concentrations, with A. radioresistens $50 \mathrm{v} 1$ having an optimal substrate concentration range with an upper limit of $2-40 \mathrm{mM}$. In contrast, the A. radioresistens type strain did not exhibit an optimal substrate concentration, and generation times (at $\leq 16 \mathrm{mM}$ ethanol) were approximately twofold slower than all tested strains. These comparisons support a trend between lower optimal substrate concentrations and spacecraft association, which would be a necessary correlation for any postulated metabolism under the oligotrophic conditions of the assembly facilities.

For this study, all downstream analyses focused on $A$. radioresistens $50 \mathrm{v} 1$, which is the best characterized strain among the spacecraft-associated Acinetobacter; in addition, at the species level, A. radioresistens has been detected on Mars-bound spacecraft and in the ISS (surfaces and drinking water) (La Duc et al., 2003; Castro et al., 2004; McCoy et al., 2012; Moissl-Eichinger et al., 2013; Schuerger et al., 2013; Derecho et al., 2014). For A. radioresistens 50v1, use of ethanol as a sole carbon source was confirmed through stable isotope labeling (using ${ }^{13} \mathrm{C}$-labeled ethanol) and untargeted analyses, which supported full enrichment of ${ }^{13} \mathrm{C}$ in the primary metabolome. Consistent with the known microbiology of A. radioresistens (Nishimura et al., 1988), 2-propanol (isopropyl alcohol, isopropanol) did not serve as a sole carbon source; however, cultivations on mixtures of ethanol and 2propanol (70/30 and 50/50 mixtures) showed enhanced growth, as indicated by statistically significant increases in plate counts $(\mathrm{cfu} / \mathrm{mL})$ at mole ratios of $\leq 0.50$.

Biochemical interrogations supported the oxidation of both ethanol and 2-propanol by extracts of $A$. radioresistens $50 \mathrm{v} 1$, likely due to a membrane-associated alcohol dehydrogenase (Singer and Finnerty, 1985). Michaelis-Menten kinetics provided a low $K_{\mathrm{M}}$ value for ethanol $(\sim 0.3 \mu \mathrm{M})$, consistent with the faster generation times obtained at the lower ethanol concentrations in ultraminimal medium. Kinetic studies also indicated a requisite need for both $\mathrm{NAD}^{+}$and an exogenous electron acceptor (XTT or DCIP), thereby supporting the formation of NADH (although transiently in cellular extracts) from either alcohol substrate, which in vivo (and in the presence of intact membranes) would directly support respiration.

Molecular and cultivation studies show that the floor of the assembly facilities also harbor strains of Acinetobacter (Ghosh et al., 2010; La Duc et al., 2012), with human-based activities possibly assisting in physical transport of these microbes across the facilities. Molecular experiments with A. radioresistens 50v1 show that Kleenol 30, an alkaline floor detergent, is biodegraded under ultraminimal conditions into lower molecular weight ethylene glycols.

Furthermore, untargeted analysis of the extracellular metabolome showed decreased abundances for several hydroxyand ketoacids in the presence of Kleenol 30. Interestingly, these hydroxy- and ketoacids share iron-binding properties (Drechsel et al., 1993; Schofield and Zhang, 1999; Yue et al., 2003) and, hence, reveal a potential impact to the transport/ metabolism of extracellular iron. Our studies also indicate that decanoate (formed during incubation in Kleenol 30 in $0.2 \times \mathrm{M} 9 / \mathrm{Fe} /$ ethanol) is biodegraded by $A$. radioresistens $50 \mathrm{v} 1$ (Fig. 5), with the results (Fig. 5B) suggesting concomitant increases in abundances of suberic acid (octanedioic acid), which along with acetyl-CoA would potentially be a metabolic product of $\omega$-oxidation of decanoate (Donoghue and Trudgill, 1975; Kunz and Weimer, 1983; Van Bogaert et al., 2011).

Under ultraminimal conditions, we also show that $A$. radioresistens 50v1 exhibits a remarkable oxidative extremotolerance when cultivated on ethanol as a sole carbon source $\left(\sim 1.5-\log\right.$ reduction, $\left.\sim 10^{8} \mathrm{cfu} / \mathrm{mL}, 10 \mathrm{mM} \mathrm{H}_{2} \mathrm{O}_{2}\right)$. This assessment is based on comparisons with other nonspore forming radiation and oxidation-resistant bacteria. For instance, the survivability of $A$. radioresistens $50 \mathrm{v} 1$ in nutrient-poor medium is comparable with that of Deinococcus radiodurans $\mathrm{R} 1\left(\sim 1-\log\right.$ reduction in $\left.33 \mathrm{mM} \mathrm{H}_{2} \mathrm{O}_{2}\right)$ and that of Vibrio rumoiensis $\mathrm{S}-1 \mathrm{~T}(\sim 1.5-\log$ reduction in $0.4 \mathrm{mM} \mathrm{H}_{2} \mathrm{O}_{2}$ ) when cultivated in nutrient-rich medium (e.g., LB, tryptic soy broth, and peptone yeast extract starch) (Arrage et al., 1993; Ichise et al., 1999). Hence, by extension, these results support the potential for oxidative extremotolerance under oligotrophic conditions, which is significant, as desiccating environments (such as the assembly facilities) are thought to promote oxidative stress through the formation of reactive oxygen species (Billi and Potts, 2002; Franca et al., 2007).

In the context of survival in the assembly facilities, therefore, these combined results support the potential for ethanol, 2-propanol, and perhaps Kleenol 30 to (1) serve as carbon or energy sources under oligotrophic conditions and (2) sustain extremotolerances against the oxidative stresses associated with low-humidity environments. For recent Mars missions, however, the surface cleaning procedures were predominantly performed using isopropyl alcohol wipes (rather than ethanol) (La Duc et al., 2012; Benardini et al., 2014). Accordingly, and as a potential survival mechanism, members of the core microbiome likely remained on the surface after wiping, wetting by the residual cleaning reagents likely initiated a basal metabolic activity, and the resulting activity was likely attenuated upon evaporation of the cleaning reagents (analogous to our experiments using loosely capped culture tubes).

In turn, the cycles of wetting/drying, resulting from highfrequency cleaning, likely imposed certain stresses (such as oxidative stress) on the microorganisms, with the residual evaporates forming a baseline vapor abundance in the facilities. In support, recent measurements show that the vapor abundances of 2-propanol are $\sim 0.1 \mathrm{ppm}$ in facilities maintained at ISO classes 8 and 7 standards (Dworkin et al., 2018); hence, these observations support the potential for 2-propanol to serve as a perpetual nutrient source, as the acquisition of volatile organics is a known survival tactic for soil bacteria (Hanzel et al., 2011; Modrzyński et al., 2016). In this combined perspective, and after substrate acquisition, the Acinetobacter could have slowly metabolized 2-propanol to yield minimal but potentially sufficient amounts of NADH to support survival. Moreover, when accounting for surface communities within the assembly facilities, our work opens the possibility that metabolic contributions may arise from other members of the core spacecraft microbiome.

\section{Conclusion}

In sum, this study provides a plausible biochemical rationale to the observed microbial ecology dynamics of spacecraft assembly facilities, as spacecraft-associated microorganisms (such as the Acinetobacter) may metabolize/ biodegrade spacecraft cleaning reagents and exhibit extreme 
oxidative tolerances under the oligotrophic and lowhumidity conditions. This work also adds to the range of known survival features for the spacecraft-associated Acinetobacter, which include extreme tolerances toward aqueous hydrogen peroxide, under nutrient-poor (this study) and nutrient-rich conditions (Derecho et al., 2014), desiccation (McCoy et al., 2012), sequential exposures to oxidative and radiative stressors (McCoy et al., 2012), heat treatments $\left(80^{\circ} \mathrm{C}\right.$ for $\left.15 \mathrm{~min}\right)$ (Moissl-Eichinger et al., 2013), and exposures to martian atmospheric and pressure conditions (Schuerger et al., 2013).

In the framework of planetary protection, therefore, the Gram-negative and nonspore forming Acinetobacter may tolerate partial sterilizations with vaporous hydrogen peroxide, and survive the heat treatments associated with the NASA Standard Assay, which could possibly impact treatments and measurements for missions requiring very low bioburden values (e.g., life detection and Special Regions missions). Furthermore, our work lends support toward the use of differing (and rotating) spacecraft-compatible cleaning reagents as a means of controlling the core spacecraft microbiome.

\section{Acknowledgments}

Special thanks go to Robert Wedge, Tynan Young, Nestor Aquino, Omar Mercado, Alexa Wollen, and Tyfanni Nguyen for their contributions. This study was funded and supported by the Faculty mini-grant program (R.M.), Provost-Teacher Scholar program (R.M.), College of Science (G.B.), and the Chemistry and Biochemistry Department (R.M. and G.B.) at Cal Poly Pomona.

\section{Author Contributions}

All listed authors contributed to the acquisition, analysis, or interpretation of the data, and drafting of critical revisions/reports of the work. The primary investigator and corresponding author is R.M. Enzymology experiments were conducted by R.B., H.B., V.N., and G.S. Survivability experiments in hydrogen peroxide were conducted by S.Le. Microbiological assays were conducted by M.A., I.C., T.G., S.G., M.H., C.J., E.K., T.N., A.O., J.R., M.S., N.T., and J.W. Cultivation experiments with Kleenol 30 were conducted by SLa and SM, whereas those with stable isotopes were conducted by N.P. G.B. supervised and directed the isotope labeling and metabolite profiling by S.La, S.M., and N.P.

\section{Author Disclosure Statement}

No competing financial interests exist.

\section{References}

Abbott, B.J., Laskin, A., and McCoy, C. (1973) Growth of Acinetobacter calcoaceticus on ethanol. Appl Microbiol 25: 787-792.

Arrage, A., Phelps, T., Benoit, R., and White, D. (1993) Survival of subsurface microorganisms exposed to UV radiation and hydrogen peroxide. Appl Environ Microbiol 59:3545-3550.

Barding, G.A., Jr., Béni, S., Fukao, T., Bailey-Serres, J., and Larive. C.K. (2013) Comparison of GC-MS and NMR for metabolite profiling of rice subjected to submergence stress. $J$ Proteome Res 12:898-909.
Barengoltz, J.B. (1997) Microbiological cleanliness of the Mars Pathfinder spacecraft, Los Angeles, California, USA. Available online at http://hdl.handle.net/2014/21747

Begot, C., Desnier, I., Daudin, J.D., Labadie, J.C., and Lebert, A. (1996) Recommendations for calculating growth parameters by optical density measurements. J Microbiol Methods 25:225-232.

Benardini, J.N., III., La Duc, M.T., Beaudet, R.A., and Koukol, R. (2014) Implementing planetary protection measures on the Mars Science Laboratory. Astrobiology 14:27-32.

Bergogne-Bérézin, E., Friedman, H., and Bendinelli, M. (2008) Acinetobacter: Biology and Pathogenesis. Springer-Verlag, New York.

Billi, D., and Potts, M. (2002) Life and death of dried prokaryotes. Res Microbiol 153:7-12.

Castro, V.A., Thrasher, A.N., Healy, M., Ott, C.M., and Pierson, D.L. (2004) Microbial characterization during the early habitation of the International Space Station. Microb Ecol 47:119-126.

Derecho, I., McCoy, K.B., Vaishampayan, P., Venkateswaran, K., and Mogul, R. (2014) Characterization of hydrogen peroxide-resistant Acinetobacter species isolated during the Mars Phoenix spacecraft assembly. Astrobiology 14:837-847.

Donoghue, N.A., and Trudgill, P.W. (1975) The metabolism of cyclohexanol by Acinetobacter NCIB 9871. FEBS J 60:1-7.

Drechsel, H., Thieken, A., Reissbrodt, R., Jung, G., and Winkelmann, G. (1993) Alpha-keto acids are novel siderophores in the genera Proteus, Providencia, and Morganella and are produced by amino acid deaminases. J Bacteriol 175:2727-2733.

Du Preez, J., Toerien, D., and Lategan, P. (1981) Growth parameters of Acinetobacter calcoaceticus on acetate and ethanol. Appl Microbiol Biotechnol 13:45-53.

Dworkin, J., Adelman, L., Ajluni, T., Andronikov, A., Aponte, J., Bartels, A., Beshore, E., Bierhaus, E., Brucato, J., and Bryan, B. (2018) OSIRIS-REx contamination control strategy and implementation. Space Sci Rev 214:19.

Franca, M.B., Panek, A.D., and Eleutherio, E.C. (2007) Oxidative stress and its effects during dehydration. Comp Biochem Physiol A Mol Integr Physiol 146:621-631.

Frick, A., Mogul, R., Stabekis, P., Conley, C.A., and Ehrenfreund, P. (2014) Overview of current capabilities and research and technology developments for planetary protection. $A d v$ Space Res 54:221-240.

Füzfai, Z., Boldizsár, I., and Molnar-Perl, I. (2008) Characteristic fragmentation patterns of the trimethylsilyl and trimethylsilyloxime derivatives of various saccharides as obtained by gas chromatography coupled to ion-trap mass spectrometry. J Chromatogr A 1177:183-189.

Ghosh, S., Osman, S., Vaishampayan, P., and Venkateswaran, K. (2010) Recurrent isolation of extremotolerant bacteria from the clean room where Phoenix spacecraft components were assembled. Astrobiology 10:325-335.

Hanzel, J., Thullner, M., Harms, H., and Wick, L.Y. (2011) Microbial growth with vapor-phase substrate. Environ Pollut 159:858-864.

Ichise, N., Morita, N., Hoshino, T., Kawasaki, K., Yumoto, I., and Okuyama, H. (1999) A mechanism of resistance to hydrogen peroxide in Vibrio rumoiensis S-1. Appl Environ Microbiol 65:73-79.

Kunz, D.A., and Weimer, P.J. (1983) Bacterial formation and metabolism of 6-hydroxyhexanoate: evidence of a potential role for omega-oxidation. J Bacteriol 156:567-575.

La Duc, M.T., Dekas, A., Osman, S., Moissl, C., Newcombe, D., and Venkateswaran, K. (2007) Isolation and characterization 
of bacteria capable of tolerating the extreme conditions of clean room environments. Appl Environ Microbiol 73: 2600-2611.

La Duc, M.T., Nicholson, W., Kern, R., and Venkateswaran, K. (2003) Microbial characterization of the Mars Odyssey spacecraft and its encapsulation facility. Environ Microbiol 5:977-985.

La Duc, M.T., Kern, R., and Venkateswaran, K. (2004) Microbial monitoring of spacecraft and associated environments. Microb Ecol 47:150-158.

La Duc, M.T., Vaishampayan, P., Nilsson, H.R., Torok, T., and Venkateswaran, K. (2012) Pyrosequencing-derived bacterial, archaeal, and fungal diversity of spacecraft hardware destined for Mars. Appl Environ Microbiol 78:5912-5922.

Mahnert, A., Vaishampayan, P., Probst, A.J., Auerbach, A., Moissl-Eichinger, C., Venkateswaran, K., and Berg, G. (2015) Cleanroom maintenance significantly reduces abundance but not diversity of indoor microbiomes. PLoS One 10:e0134848.

McCoy, K., Derecho, I., Wong, T., Tran, H., Huynh, T., La Duc, M., Venkateswaran, K., and Mogul, R. (2012) Insights into the extremotolerance of Acinetobacter radioresistens $50 \mathrm{v} 1$, a gram-negative bacterium isolated from the Mars Odyssey spacecraft. Astrobiology 12:854-862.

Modrzyński, J.J., Christensen, J.H., Mayer, P., and Brandt, K.K. (2016) Limited recovery of soil microbial activity after transient exposure to gasoline vapors. Environ Pollut 216: 826-835.

Moissl, C., Osman, S., La Duc, M.T., Dekas, A., Brodie, E., DeSantis, T., and Venkateswaran, K. (2007) Molecular bacterial community analysis of clean rooms where spacecraft are assembled. FEMS Microbiol Ecol 61:509-521.

Moissl-Eichinger, C., Pukall, R., Probst, A.J., Stieglmeier, M., Schwendner, P., Mora, M., Barczyk, S., Bohmeier, M., and Rettberg, P. (2013) Lessons learned from the microbial analysis of the Herschel spacecraft during assembly, integration, and test operations. Astrobiology 13:1125-1139.

NASA. (2011) Planetary Protection Provisions for Robotic Extraterrestrial Missions. National Aeronautics and Space Administration. Available online at http://nodis3.gsfc.nasa .gov/displayDir.cfm?Internal_ID=N_PR_8020_012D_\&page_ name $=$ main $\&$ search_term $=8020 \% 2 \mathrm{E} 12$

Nishimura, Y., Ino, T., and Iizuka, H. (1988) Acinetobacter radioresistens $\mathrm{sp}$. nov. isolated from cotton and soil. Int J Syst Evol Microbiol 38:209-211.

Pirog, T., and Kuz'minskaya, Y.V. (2003) Some characteristics of central metabolism in Acinetobacter sp. grown on ethanol. Microbiology 72:408-413.

Schofield, C.J., and Zhang, Z. (1999) Structural and mechanistic studies on 2-oxoglutarate-dependent oxygenases and related enzymes. Curr Opin Struct Biol 9:722-731.

Schuerger, A.C., Ulrich, R., Berry, B.J., and Nicholson, W.L. (2013) Growth of Serratia liquefaciens under $7 \mathrm{mbar}, 0^{\circ} \mathrm{C}$, and $\mathrm{CO}_{2}$-enriched anoxic atmospheres. Astrobiology 13:115-131.
Singer, M., and Finnerty, W. (1985) Alcohol dehydrogenases in Acinetobacter sp. strain HO1-N: role in hexadecane and hexadecanol metabolism. J Bacteriol 164:1017-1024.

Space Studies Board. (2000) Preventing the forward contamination of Europa. National Academy Press, Washington D.C. Space Studies Board. (2006) Preventing the forward contamination of Mars. National Academies Press, Washington D.C.

Vaishampayan, P., Osman, S., Andersen, G., and Venkateswaran, K. (2010) High-density 16S microarray and clone library-based microbial community composition of the Phoenix spacecraft assembly clean room. Astrobiology 10:499-508.

Vaishampayan, P., Probst, A.J., La Duc, M.T., Bargoma, E., Benardini, J.N., Andersen, G.L., and Venkateswaran, K. (2013) New perspectives on viable microbial communities in low-biomass cleanroom environments. ISME J 7:312-324.

Van Bogaert, I.N., Groeneboer, S., Saerens, K., and Soetaert, W. (2011) The role of cytochrome P450 monooxygenases in microbial fatty acid metabolism. FEBS J 278:206-221.

Venkateswaran, K., Satomi, M., Chung, S., Kern, R., Koukol, R., Basic, C., and White, D. (2001) Molecular microbial diversity of a spacecraft assembly facility. Syst Appl Microbiol 24:311-320.

Yue, W.W., Grizot, S., and Buchanan, S.K. (2003) Structural evidence for iron-free citrate and ferric citrate binding to the TonB-dependent outer membrane transporter FecA. J Mol Biol 332:353-368.

Address correspondence to: Rakesh Mogul

Chemistry \& Biochemistry Department California State Polytechnic University, Pomona (Cal Poly Pomona) 3801 W. Temple Ave.

Pomona, CA 91768

E-mail:rmogul@cpp.edu

Submitted 30 December 2017

Accepted 23 March 2018

Associate Editor: Petra Rettberg

\begin{aligned} & \multicolumn{1}{c|}{ Abbreviations Used } \\ & FAMEs $=$ fatty acid methyl esters \\ & GC-MS $=$ gas chromatography-mass spectrometry \\ & ISS $=$ International Space Station \\ & LB $=$ Lysogeny broth \\ & MSTFA $=N$-methyl- $N$-(trimethylsilyl)trifluoroacetamide \\ & $\mathrm{OD}=$ optical density \\ & $\mathrm{PBS}=$ phosphate-buffered saline \\ & $\mathrm{RT}=$ retention time \end{aligned}

